\title{
O Sistema Único de Saúde na representação social de usuários: uma análise de sua estrutura
}

\author{
The Unified Health System in the users' social representation: an analysis of its structure
}

El Sistema Único de Salud en la representación social de usuarios: un análisis de su estructura

\section{Antonio Marcos Tosoli Gomes', Denize Cristina de Oliveira', Celso Pereira de Sá"}

' Universidade do Estado do Rio de Janeiro, Faculdade de Enfermagem. Rio de Janeiro-RJ, Brasil. " Universidade do Estado do Rio de Janeiro, Programa de Pós-Graduação em Psicologia Social. Rio de Janeiro-RJ, Brasil

Submissão: 26/10/2009 Revisão: 7/11/2010 Aprovação: 11/1/2011

\section{RESUMO}

Este estudo tem como objetivo analisar a estrutura representacional de um grupo de usuários do SUS na cidade do Rio de Janeiro acerca do próprio sistema. De caráter qualitativo, foi desenvolvido com o suporte da teoria do núcleo central das representações sociais, com 104 usuários de cinco instituições de saúde. Os dados foram coletados através de evocações livres ao termo indutor SUS e analisados pelo software EVOC 2000. A estrutura da representação revelou quatro dimensões, a conceitual, a avaliativa, a espacial e a de finalidade, que apresentaram, respectivamente, os seguintes léxicos em seu núcleo central: saúde, bem atendido, hospital e atendimento. Observam-se elementos de contraste negativos em meio à representação positiva do sistema e a presença de todas as dimensões na periferia, com predomínio da dimensão finalidade. Conclui-se que o sistema apresenta-se de forma pragmática para os sujeitos e que a concretização de sua implementação ainda se faz necessária. Descritores: Psicologia Social; Enfermagem, Sistemas de Saúde.

\begin{abstract}
The objective of this study was to analyze the representational structure of a group of users of the Unified Health System (SUS) in the city of Rio de Janeiro, Brazil, concerning the system. A qualitative research, grounded on the theory of the central nucleus of the social representations, was developed with 104 users of five health care facilities. Data were collected through the free evocation to the inducer term SUS, and analyzed by the software EVOC 2000. The structure of the representation disclosed four dimensions: conceptual, evaluative, spatial, and finalistic. They presented, respectively, the following lexicons in their central nucleus: health, well attended, hospital and attendance. Negative elements of contrast were found amidst the positive representation of the system and the presence of all four dimensions was observed in the periphery, with predominance of the finalistic one. The conclusion is that the system presents itself to the citizens in a pragmatic way and that its implementation is still necessary.
\end{abstract}

Key words: Social Psychology; Nursing; Health Systems.

\section{RESUMEN}

Este estudio tuve como objetivo analizar la estructura representacional de un grupo de los usuarios del Sistema Único de Salud en la ciudad de Rio de Janeiro, Brasil, referente al sistema. De carácter cualitativo, fue desarrollado con base en la teoría del núcleo central de las representaciones sociales, con 104 usuarios de 5 instituciones de salud. Los datos fueran recogidos a través de evocaciones libres al termo inductor SUS y analizados por software EVOC 2000. La estructura de la representación ha revelado cuatro dimensiones, la conceptual, el evaluativa, la espacial y la de finalidad, que presentaran, respectivamente, los siguientes léxicos en su núcleo central: la salud, bien cuidado, el hospital y la atención. Se observaran elementos negativos de contraste en la representación positiva de sistema y la presencia de todas las dimensiones en la periferia, con predominio de la dimensión finalidad. Se concluye que el sistema se presenta de forma pragmática para los ciudadanos y que la concreción de su ejecución aún es necesaria.

Palabras clave: Psicología Social; Enfermería; Sistemas de Salud. 


\section{INTRODUÇÃO}

Após vinte anos de sua existência, o Sistema Único de Saúde (SUS) se constituiu como um instrumento de cidadania a partir de seu perfil inclusivo, deitando raízes nas transformações sociais realizadas ou desejadas no fim de um dos períodos mais difíceis do país. Dessa maneira, o SUS extrapola os limites de um órgão estatal que tem o objetivo de oferecer saúde, sendo alimentado e alimentando um processo social mais amplo que, ao longo dos anos, sofreu avanços e retrocessos e comportou-se ora como os seus objetivos preconizavam e ora sendo reduzido, normalmente a partir de manobras políticas, a uma atenção pontual à saúde ${ }^{(1)}$.

O SUS influenciou a noção e a vivência de saúde no Brasil, especialmente quando se destaca que é um país de dimensões continentais e com características sociais peculiares. Além disso, o que mais o caracterizou, desde o início, foi o fato de ter aberto as portas das instituições para todos os brasileiros serem atendidos sem nenhum tipo de discriminação, ainda que a implementação desse processo não tenha se concretizado completamente.

Neste percurso, ao longo de todos esses anos, muitas coisas foram ditas acerca do sistema, como o seu perfil, os seus objetivos, os seus desafios e as suas dificuldades. Diversos atores sociais foram ouvidos, pronunciamentos foram feitos, desvios de verbas descobertos e o mesmo teve continuidade, construindo-se no que se apresenta hoje. Inúmeras reportagens foram escritas, a favor ou contra, mostrando os seus pontos fortes ou destacando os nós do processo de sua implementação. No entanto, um ponto ainda necessita de um aprofundamento: oferecer voz para que os usuários do sistema possam expressar a sua opinião. Neste sentido objetiva-se neste trabalho analisar a estrutura representacional de um grupo de usuários do SUS na cidade do Rio de Janeiro acerca do próprio sistema.

A importância deste trabalho se centra na possibilidade de oferecer um espaço para que as representações dos usuários possam ser recuperadas e discutidas. Ao considerarmos as representações como reconstrução de uma realidade vivida, sentida, enfrentada e negociada pelo diálogo e pelas informações recebidas, pode-se perceber que este estudo possibilitará a apreensão de como o sistema se apresenta no cotidiano dos sujeitos, na atenção às suas necessidades, no desenvolvimento de suas ações e nas dificuldades enfrentadas.

Ao mesmo tempo, as representações sociais têm profundas implicações nas atitudes adotadas na vida cotidiana, o que aumenta o interesse em estudar as representações do SUS, de modo a compreendermos os posicionamentos e os interesses dos atores sociais no âmbito do sistema.

\section{METODOLOGIA}

Como já destacado, adotou-se para a orientação deste estudo a Teoria das Representações Sociais ${ }^{(2)}$, a partir da proposta complementar denominada abordagem estrutural ou Teoria do Núcleo Central. ${ }^{(3)}$ Define-se representações sociais, neste contexto, como sendo o produto e o processo de uma atividade mental, através do qual um indivíduo ou um grupo reconstitui a realidade com a qual ele se confronta e para a qual ele atribui um significado específico. ${ }^{(4)}$ No que tange à abordagem complementar supracitada, destaca-se que esta considera que a organização de uma representação social apresenta uma característica específica, a de ser organizada em torno de um núcleo central, constituindo-se em um ou mais elementos que dão significado à representação, fornecendo o sentido fundamental e inflexível à mesma. ${ }^{(3)}$

O desenho metodológico envolveu cinco instituições de saúde localizadas na cidade do Rio de Janeiro, que tinham sido constituídas antes da implantação do SUS, de modo que tivessem construído uma história dentro do sistema de saúde brasileiro. A escolha das instituições obedeceu aos seguintes critérios: um hospital público federal; um hospital estadual geral; um hospital municipal; um hospital privado, conveniado com o SUS, há pelo menos 21 anos; e um centro de saúde pertencente à rede pública municipal de saúde.

A coleta de dados foi realizada no primeiro semestre de 2007 com 104 profissionais que desenvolviam ações no âmbito das instituições selecionadas, aproximadamente 21 de cada unidade, que atuavam nas respectivas instituições há pelo menos 21 anos. A escolha dos sujeitos obedeceu ao seguinte critério de inclusão: ter sido atendido nas respectivas instituições antes da implantação do SUS.

A coleta de dados foi realizada através da técnica de evocações livres que busca apreender a percepção da realidade a partir de uma composição semântica preexistente, composição esta normalmente não só concreta, mas também imagética, organizada ao redor de alguns elementos simbólicos simples. Nesse sentido, a aplicação prática do teste consiste em pedir aos sujeitos que associem, livre e rapidamente, a partir da audição ou visualização de palavras indutoras (estímulos), outras palavras ou expressões, no nosso caso a expressão Sistema Único de Saúde.

Para o tratamento dos dados coletados foi utilizado o software EVOC (Ensemble de Programmes Pemettant L'Analyse des Evoctions), versão 2000, que possibilita efetuar a organização das palavras produzidas em função da hierarquia implícita à freqüência e à ordem natural de evocação. A técnica de análise consiste em construção de um quadro de quatro casas no qual são distribuídas as palavras evocadas, considerando os critérios de maiores freqüências e ordem média de evocação $(\mathrm{OME})^{(5)}$.

No tocante aos aspectos éticos da pesquisa, foram respeitados os princípios da Resolução 196/96. O projeto foi aprovado pelo Comitê de Ética em Pesquisa (CEP) da Universidade do Estado do Rio de Janeiro (Parecer $\left.n^{\circ} 006 / 2005\right)$ e pelas instituições participantes, além da autorização dos sujeitos, expressa na assinatura do Termo de Consentimento Livre e Esclarecido.

\section{APRESENTAÇÃO E DISCUSSÃO DOS DADOS}

Os resultados são organizados no que é chamado de Quadro de quatro casas, sendo o quadrante superior à esquerda denominado de núcleo central, a parte mais estável e permanente em uma representação, conferindo-lhe sentido; o inferior, à esquerda, denomina-se zona de contraste, onde pode ser percebido um subgrupo representacional, o que significa dizer que ele pode demonstrar grupos que pensam de modo diferente 


\begin{tabular}{|c|c|c|c|c|c|c|}
\hline O.M.E. & \multicolumn{3}{|l|}{$<3,02$} & \multicolumn{3}{|l|}{$\geq 3,02$} \\
\hline Freq. Med. & Termo evocado & Freq. & O.M.E. & Termo evocado & Freq. & O.M.E. \\
\hline$\geq 15$ & $\begin{array}{l}\text { Saúde(/) } \\
\text { Bem-atendido(*) } \\
\text { Hospital(-) } \\
\text { Atendimento(+) }\end{array}$ & $\begin{array}{l}31 \\
21 \\
16 \\
15\end{array}$ & $\begin{array}{l}1,7 \\
2,9 \\
2,6 \\
2,7\end{array}$ & $\begin{array}{l}\text { Remédio(+) } \\
\text { Fila }\left(^{*}\right) \\
\text { Demora }(*) \\
\text { Exame }(+)\end{array}$ & $\begin{array}{l}20 \\
16 \\
15 \\
13\end{array}$ & $\begin{array}{l}3,5 \\
3,53 \\
3,8 \\
4,2\end{array}$ \\
\hline$<15$ & $\begin{array}{l}\text { Atendimento - ruim }\left(^{*}\right) \\
\operatorname{Ruim}(*) \\
\text { Sem-queixa }\left(^{*}\right) \\
\text { Bom }\left(^{*}\right) \\
\text { Tristeza }(*) \\
\text { Médico(/) }\end{array}$ & $\begin{array}{l}14 \\
14 \\
13 \\
10 \\
10 \\
8\end{array}$ & $\begin{array}{l}2,9 \\
1,9 \\
2,3 \\
2,5 \\
2,0 \\
2,3\end{array}$ & $\begin{array}{l}\text { Atender - todos }(+) \\
\text { Emergência(-) } \\
\text { Desigualdade }\left(^{*}\right) \\
\text { Internação(+) } \\
\text { Limpeza }(+) \\
\text { Baixa - renda(/) }\end{array}$ & $\begin{array}{l}10 \\
9 \\
8 \\
8 \\
8 \\
8\end{array}$ & $\begin{array}{l}3,3 \\
3,8 \\
3,7 \\
3,5 \\
3,3 \\
3,2\end{array}$ \\
\hline
\end{tabular}

Legenda: Dimensão avaliativa(*), de finalidade(+), espacial(-) e conceitual(/)

\section{Quadro 1 - Quadro de quatro casas, com a estrutura da representação social dos usuários estudados das cinco instituições de saúde. Rio de Janeiro, 2007.}

da maioria. Os dois quadrantes à direita são a primeira periferia (superior) e a segunda (inferior), que expressam o contexto imediato que as pessoas vivem, o seu contato com a realidade.

Os usuários do Sistema Único de Saúde, a partir de suas experiências e vivências, bem como das informações recebidas e dialogadas diariamente com os profissionais, outros usuários e seu círculo social, construíram uma maneira peculiar de entender o sistema, atribuindo-lhe sentido e assumindo posições a partir dessa mesma compreensão. Dessa maneira, o grupo estudado e o sistema (por meio de seus agentes, do investimento governamental, das propagandas, do serviço oferecido e da estrutura existente) se envolvem, de forma conjunta, na reconstrução desse mesmo sistema, superando a dicotomia existente entre o interno e o externo do próprio sujeito em um movimento dinâmico, misturando imagens, conhecimentos, opiniões alheias, consensos sociais hegemônicos e vários outros processos interativos e de construções subjetivas.

O grupo de usuários, em função do estímulo usado na produção dos dados, ligou diversas palavras ao sistema de saúde consubstanciando um mundo semântico para este objeto, de forma espontânea e com o menor controle mental possível. Para que pudéssemos compreender este mundo semântico, foi necessário agrupar as palavras usadas pelos sujeitos e, assim, compreender o sentido empregado pelos mesmos. Esse agrupamento de sentido gerou quatro dimensões: a avaliativa, a de finalidade, a espacial e a conceitual.

A dimensão avaliativa expõe o julgamento realizado pelos usuários acerca do SUS. Esta avaliação começa no próprio centro da representação acerca do sistema, com a expressão bem atendido, incluindo, neste contexto, um aspecto prático no processo de reconstrução cognitiva do SUS. Isto implica dizer que os usuários moldaram processo representacional em íntima relação com a sua experiência prática e cotidiana dentro do sistema.
Dessa maneira, pode-se observar que o SUS é entendido à medida que também é, não só palpável, mas também alcançado em meio aos dramas históricos, sociais e do processo saúde-doença vividos por estes atores socais. Ou seja, os aspectos teóricos, legais, éticos e jurídicos do sistema só possuem aderência à organização do pensamento do grupo à medida que possuir relação com o cotidiano pessoal, transformando-se em direitos, em relações interpessoais e em acessos à ações e aos serviços em saúde ${ }^{(6)}$.

Chama a atenção, ainda, que os sujeitos apresentem uma avaliação positiva acerca do atendimento no contexto do SUS, configurando uma base representacional eminentemente positiva, em que pese a presença de elementos negativos em outros quadrantes, inclusive em uma avaliação do próprio atendimento entre os elementos da zona de contraste, neste caso negativa. Esta positividade pode deitar raízes na abertura das portas do sistema de saúde para a população em geral, o que explica o fato da palavra atendimento possuir importância no mundo semântico apresentado, especialmente quando se lembra de que os sujeitos vivenciaram a assistência à saúde no contexto do INPS/INAMPS. Pode estar relacionada, ainda, à relação interpessoal estabelecida entre os profissionais e os usuários, à crescente cobertura das ações e dos serviços em saúde na atualidade e o paradigma da promoção à saúde presente hoje no ideário do sistema de saúde.

O Ministério da Saúde afirma que o SUS apresenta-se como fundamental no processo de manutenção da saúde, da prevenção de doenças e da recuperação da saúde para mais de 120 milhões de brasileiros, apesar dos inúmeros problemas e desafios que enfrenta na concretização da assistência à saúde em um país das dimensões do Brasil(7). A complexidade do sistema se dá, dentre outras coisas, pelo fato de abarcar os extremos do processo assistencial, que vai da oferta de ações e serviços da rede básica até procedimentos de alta tecnologia(8). 
O SUS se faz presente, de forma visível e até imagética, nas consultas dos programas da criança, da mulher e do adolescente, no âmbito da Estratégia da Saúde da Família, inclusive através das visitas domiciliares, na distribuição dos antirretrovirais para os pacientes soropositivos, na quase totalidade dos transplantes realizados, nos tratamentos dialíticos e na atenção terciária e quaternária, além de várias outras situações. Em um contexto de forte exclusão social e econômica, em que uma grande maioria de brasileiros é privada de serviços essenciais, encontrar um espaço de portas abertas - mesmo que alguns serviços não sejam alcançados, mas algum rosto será visto por trás do vidro em algum prédio - é estado de exceção, até mesmo considerado como resultado da sorte, ou de uma intervenção divina direta, como os mesmos usuários já pontuaram ${ }^{(9-10)}$.

Esta interpretação do mundo semântico é reforçada quando aparece, na centralidade da representação, um espaço típico para o atendimento, concretizando a dimensão espacial, qual seja, o hospital, este mesmo espaço que tende a apresentar um gargalo no processo de atendimento e de exclusões quando não é público ou conveniado ao SUS (diferente da rede básica, que é, por excelência, aberta a todos, ou as instituições filantrópicas que possuem uma filosofia própria, que não a financeira, para a abertura de suas portas). O aparecimento desse léxico talvez esteja correlacionado ao fato dos usuários entrevistados serem de quatro instituições hospitalares e apenas um da rede básica. No entanto, embora tenhamos de reconhecer o peso deste desenho metodológico, diversos autores ${ }^{(11-12)}$ apontam a importância que as instituições de alta tecnologia possuem no imaginário dos profissionais e da população, transformando os hospitais como uma das imagens mais visíveis do sistema de saúde, apesar dos esforços das últimas décadas na atenção básica e, especialmente, na promoção da saúde.

Desta maneira, considera-se que a importância adquirida pelo hospital no mundo semântico dos usuários não se deva, ao menos não isoladamente, como conseqüência da metodologia utilizada, mas também em função das construções sociais, culturais e sanitárias que envolvem esta instituição e seu papel na compreensão da saúde e em sua concretização prática. A história sanitária do século XX, apesar do avanço proporcionado pelas conferências internacionais e nacionais, foi marcada por um forte hospitalocentrismo e um incentivo ao consumo de tecnologias de alto custo e de procedimentos cada vez mais invasivos, necessitando de um espaço com características específicas e de profissionais especializados ${ }^{(13)}$.

A mídia, em todas as suas formas, trabalha na construção de uma associação íntima entre saúde e hospital - especialmente os privados - em que se tornou difícil pensar em saúde, felicidade e futuro sem a tendência de incluir o hospital como instância fundamental, quase reguladora do saber e do fazer dos cidadãos. Além disso, observa-se, por exemplo, que o número de hospitais tende a apresentar relação com a riqueza e o desenvolvimento de uma cidade ou de um Estado e, neste sentido, basta observar o eixo Rio - São Paulo e as histórias dessas duas capitais brasileiras em comparação com as demais.

A representação do SUS, então, mesmo que parcialmente, é identificada, até mesmo sobreposta, à do hospital, limitando, de determinada maneira, os objetivos e os alcances do sistema e fortalecendo a ideologia hospitalocêntrica em um círculo vicioso entre mídia, imagens, representações, opiniões e idéias. Este fato talvez explique a procura do hospital para demandas que poderiam ser sanadas em níveis menos complexos do sistema de saúde, mesmo quando o atendimento emergencial não se faz presente ${ }^{(14)}$. Se o sistema, para os usuários, possui uma imagem e um sentido de hospital, nada mais natural que este seja o lócus onde se encontra a saúde e a proteção contra as doenças, independente se indicação se encaixa para este nível de complexidade.

Aqui reside um ponto nevrálgico que deve ser levado em consideração pelo sistema público de saúde: torna-se premente a necessidade de um trabalho de marketing nas mídias de massa, uma atuação profissional na relação direta com a clientela e um forte processo de educação em saúde com o objetivo de que novas representações poderão gerar outras relações dos usuários com o sistema, talvez incorporando outros loci no processo de se pensar e se produzir saúde, como o posto de saúde, a estratégia da saúde da família, a escola e a igreja, por exemplo. Destaca-se aqui o poder heurístico das representações e a sua relação com a prática cotidiana, elementos importantes para o planejamento em saúde, a prática profissional e o sucesso em diversos processos implementados na unidade de saúde, como a adesão ao tratamento e a compreensão de determinadas práticas populares.

$\mathrm{Na}$ dimensão conceitual, os usuários definem o sistema único como saúde, associando o seu aspecto conceitual com o da finalidade. Ao mesmo tempo, torna-se interessante destacar o fato do mundo semântico dos usuários definir o sistema a partir do ângulo da saúde, entendendo que este termo traduz um dos bens mais preciosos do ser humano. Como consequência, pode-se depreender a importância atribuída pelos sujeitos ao sistema e o seu papel na vida de cada um deles, gerando saúde e, conseqüentemente, a continuidade da existência com o máximo de qualidade possível.

No entanto, como apontam diversos autores ${ }^{(15-16)}$, o termo saúde apresenta-se, caracteristicamente, polissêmico e, por isso, pode adquirir vários sentidos em função da formação discursiva empregada pelo autor. Diante do exposto, saúde pode ganhar conotações de ausência de doenças, limitando a sua compreensão à dimensão biomédica e patológica. Em outro extremo, este conceito pode evocar generalizações tão abstratas que não abarcam questões concretas, quando analisadas em profundidade. Mesmo a definição de saúde promulgada pela Organização Mundial da Saúde, que a compreende como um completo bem estar físico, mental e social, carece de uma dinâmica característica do processo de nascer, viver e morrer dos indivíduos ${ }^{(17-18)}$, que não possui reflexo na definição supracitada, em função de seu caráter estático que não corresponde ao ser e ao agir humanos no mundo.

O sentido utilizado pelos sujeitos à saúde parece estar desdobrado entre os elementos de contraste e na segunda periferia. Ao serem indagados sobre o sistema único de saúde, os usuários responderam médico (contraste), explicitando uma visão biomédica da saúde e reforçando a representação de saúde hegemônica na sociedade. Responderam, também, baixa-renda (segunda periferia), compreendendo o SUS como 
um atendimento para pobres. Como este último apresenta-se como uma definição, mas não fornece uma ajuda substancial no entendimento do polissêmico termo saúde, o abordaremos em sua parte específica.

Neste processo, resta-nos o binômio saúde-médico, binômio este bastante recorrente na mídia, presente nas conversas cotidianas e difundido coletivamente, bem como esclarecedor do sentido empregado no uso do primeiro termo. Ou seja, como pontuado no parágrafo acima, os indivíduos entrevistados, neste contexto, entenderam a saúde especialmente em sua dimensão biomédica, reforçando e sendo reforçada, inclusive, pela palavra atendimento, também central.

A saúde enfoca, neste caso, as patologias enfrentadas, as terapêuticas adotadas, o atendimento profissional e a solução da situação especialmente através da cura, ancorando-se no modelo biomédico ${ }^{(17)}$. Neste sentido, deve-se destacar que esta forma de compreender a saúde gerou importante evolução na tecnologia em saúde, queda nos índices de mortalidade (especialmente em doenças agudas e situações emergenciais) e aumento da perspectiva de vida. Por outro lado, transformou-se em um terreno fértil para um consumo acrítico dessas mesmas tecnologias e o estabelecimento de uma visão mecanicista e reducionista do corpo humano e suas reações.

O principal problema da ciência biomédica nos últimos anos foi o seu status de verdade que definiu um modo próprio de enxergar a saúde, excluindo totalmente outras possibilidades mesmo quando não existem respostas de sua parte. $\mathrm{O}$ tratamento de diversos tipos de cânceres seguiu esse caminho através do processo de descrédito dos conhecimentos fitoterápicos, indígenas e populares que, por não terem um método como a ciência, era considerado atrasado e ineficiente. $\mathrm{O}$ mesmo se deu com a influência da mente sobre as reações corporais e o processo de psicossomatização em que a morbidade não se localiza apensas no espaço celular ou em interações bioquímicas ${ }^{(17)}$.

Deste modo, a solução não é abrir mão da ciência biomédica, e assim dos seus benefícios, mas sim levar em consideração que ela não consegue oferecer solução para todos os problemas sanitários atuais. Ao mesmo tempo, compreender que nenhuma outra ciência apresenta-se profunda o suficiente para abarcar a complexidade humana e os desafios da atualidade.

Observa-se, ainda, no centro da representação a dimensão de finalidade, expresso, nesta parte do quadro, pela palavra atendimento. $\mathrm{O}$ atendimento configura-se como sendo o motivo pelo qual o sistema foi criado, atingindo o seu público-alvo e disponibilizando as bases e as ferramentas possíveis para gerar saúde, prevenir doenças e reduzir agravos neste encontro entre o usuário e o próprio sistema.

Ainda que as ações do SUS sejam mais amplas que o atendimento individual, é este, como já pontuado em outras dimensões, que mais tocam os usuários em função do alcance de suas necessidades, às vezes prementes. Esta situação apresenta-se ainda mais importante em se tratando de um sistema com as características universais como o SUS dentro do qual todas as necessidades sentidas e vividas pela população são englobadas com relação a um conceito mais amplo de saúde.
A própria Lei Orgânica da Saúde ${ }^{(19)}$ inclui, entre os objetivos do SUS, a identificação e a divulgação dos fatores condicionantes e determinantes da saúde; a formulação de política de saúde destinada a promover, nos campos econômico e social, a redução de riscos de doenças e de outros agravos; o estabelecimento de condições que assegurem acesso universal e igualitário às ações e aos serviços para a sua promoção, proteção e recuperação; e a assistência às pessoas por intermédio de ações de promoção, proteção e recuperação da saúde a partir da realização integrada das ações assistenciais e das atividades preventivas. Percebe-se, ainda, que os objetivos do sistema, por mais amplo que se apresentem, concretiza-se, para a maioria da população, no interior da relação profissional-clientela no contexto do atendimento ou da atenção direta.

Nesta mesma lei, o SUS adota como seu campo de ação todas as questões que estão relacionadas com a promoção da saúde e da vida humana, entendendo como condicionantes desse processo, "entre outros, a alimentação, a moradia, o saneamento básico, o meio ambiente, o trabalho, a renda, a educação, o transporte, o lazer e o acesso aos bens e serviços essenciais; os níveis de saúde da população expressam a organização social e econômica do País" (19).

Entre os elementos de contraste, a estrutura da representação mostra uma forma diferente de compreensão do sistema daquele mostrado no núcleo central, o que chamamos de sub-grupo representacional. Se a representação mostrou-se basicamente positiva, neste quadrante revela-se eminentemente negativa, comportando palavras e/ou expressões como atendimento-ruim, ruim e tristeza, Ou seja, observa-se que parte do grupo estudado possui representações negativas acerca do sistema, desdobrando-as em três áreas.

A primeira refere-se ao atendimento, construindo uma oposição à centralidade do bom atendimento e mostrando duas facetas para o mesmo fenômeno. Se a expressão bem atendido possui uma freqüência maior em sete evocações, as duas foram evocadas em uma ordem semelhante, o que implica dizer que nenhuma foi lembrada mais prontamente que a outra e que não existe uma hegemonia tão absoluta da avaliação positiva no contexto dessa representação.

Em outras publicações, já se pontuou a existência da tensão entre a positividade e a negatividade na representação do sistema de saúde, mesmo entre os profissionais ${ }^{(14)}$. Destaca-se que é importante a existência dessa tensão de modo a explicitar a complexidade da concretização do sistema, à medida que nenhuma estrutura inclusiva e universal no contexto de um país em desenvolvimento e com a dimensão do Brasil tenderá a ser considerado apenas positivo.

De forma simultânea, esse resultado questiona a constante divulgação da mídia e o marketing majoritariamente negativo realizado em cima do sistema. Apesar das inúmeras dificuldades enfrentadas pelo SUS que todos conhecem em maior ou menor grau, também é verdade que ele se caracteriza pela transformação que causou na sociedade brasileira em plena abertura política, fruto de uma mobilização e uma articulação social entre diversos seguimentos como pouco se viu nos últimos anos. O sistema tem fornecido ampla abrangência de 
ações e um crescimento constante da cobertura populacional com aperfeiçoamento de seus dispositivos, como o atendimento fora de domicílio, a internação domiciliar e os transplantes e a expansão da Estratégia da Saúde da Família.

No entanto, mesmo entre os elementos de contraste, observa-se ainda um elemento positivo (bom), reforçando a avaliação positiva presente no núcleo central, e um neutro (sem queixa). Essas presenças tendem a reforçar muito mais a interpretação de que a representação dos usuários é alicerçada em uma base positiva, mesmo tensionada com uma certa negatividade presente neste quadrante, diferenciando-se do modo como, em estudos anteriores, os profissionais representam o sistema único de saúde ${ }^{(14)}$.

No contexto da primeira periferia pode-se perceber a presença de duas dimensões, quais sejam, a de finalidade e a avaliativa, ambas apresentando forte inter-relação entre si. A primeira é concretizada a partir de dois termos, remédio e exame, enquanto a segunda, também com duas palavras, apresenta fila e demora.

A de finalidade engloba tecnologias (remédio) e ações (exames) de saúde que são carros-chefe na estrutura sanitária ocidental. Com a evolução tecnológica, a atenção à saúde organizou-se, basicamente, ao redor dos diferentes fármacos que possuem suas ações em áreas e estruturas cada vez menores do organismo humano, oferecendo soluções à situações de grande sofrimento para os indivíduos, mas provocando reações em outras estruturas corporais, uma vez que a ação no micro-espaço não tem levado em consideração as inter-relações existentes na complexidade das funções corporais.

Seja como for, o fato é que, ao longo do tempo, descobriu-se um medicamento para cada infecção, para cada dor e para cada agressão sofrida, sofisticando a química à medida que mais se conheciam os detalhes do funcionamento fisiológico, bioquímico e histológico do homem. A imagem de modernidade e resolutividade que foi criada (e facilmente aderida) para essas composições químicas fez com que toda a atenção à saúde (inclusive de profissões, como a Enfermagem, que não possuem, no âmbito de suas competências regulares, a prescrição medicamentosa) se organizasse ao seu redor, mesmo com a advertência de vários pesquisadores sobre o baixo impacto na saúde da população em geral e do alto custo que este tipo de terapia exige ${ }^{(20-21)}$.

Alguns autores mostram que uma das ações mais valorizadas pelos usuários na cidade do Rio de Janeiro é a dispensação de medicamentos em domicílio, especialmente aqueles prescritos no âmbito dos programas de saúde, como hipertensão e diabetes $^{(9-10)}$. Os sujeitos pontuaram que não é a comodidade de recebê-los em casa que os impressionam, mas o fato de ter acesso a tal tecnologia de maneira tão organizada e prática.

Em um processo muito similar, os exames de apoio diagnóstico tornaram-se centrais no modo de se compreender e fazer saúde, apresentando-se como indispensáveis ao fechamento diagnóstico e representando um importante afastamento do contato dos profissionais com a clientela. A partir de sua utilização, a arte da diagnose através da clínica, do toque profissional e da compreensão do corpo humano a partir da relação interpessoal foi preterida por imagens e dados bioquímicos que descrevem, com precisão, o que está acontecendo no interior do corpo do paciente.

Potencializando este fato, o apoio clínico, de per si, foi ficando ultrapassado quando comparado à capacidade do maquinário usado para a detecção das micro-alterações. De resto, nesta relação sobrou a desconfiança: a desconfiança do profissional em seu próprio conhecimento - semiologia, clínica, epidemiologia - que possui, sem a perfeita conexão com a tecnologia dura, uma representação de ultrapassada pelos modernos meios diagnósticos; a desconfiança deste mesmo profissional, de que nem o paciente e nem o tribunal os perdoará caso algo não tenha o desfecho desejado e os instrumentais mais modernos não tenham sido usados (mesmo que só para confirmar o que os profissionais, pela experiência e sensibilidade, já sabiam); e a desconfiança do usuário, que prefere confiar na objetividade de um resultado da informática do que na experiência dos profissionais.

$\mathrm{Na}$ esteira dos medicamentos, desenvolveu-se uma série de exames cada vez mais específicos, com maior sensibilidade e menor abrangência, onerando cada vez mais os diferentes tratamentos em saúde e, conseqüentemente, gerando um processo de exclusão daqueles que não possuem estrutura financeira para tal. Alguns autores já pontuavam a excessiva utilização dessa tecnologia sem o retorno financeiro ou social para o sistema de saúde, com uma enxurrada de indicações inadequadas que não possuem impacto na evolução do processo saúde-doença individual e nem importância do ponto de vista epidemiológico ${ }^{(17,20)}$.

Chama a atenção como o modelo biomédico da saúde manteve-se presente na representação do sistema de saúde, jogando ainda mais luz à compreensão deste termo. $\mathrm{O}$ modo de se pensar e de se compreender o SUS, para os sujeitos, está atravessado pelas compreensões tecnológica, farmacológica e medicalizada do processo saúde-doença, em que pese os objetivos do sistema contidos em sua própria legislação, como expostos alguns parágrafos acima.

Deve-se ressaltar a importância dos exames de apoio diagnóstico e dos medicamentos para a solução de diversos problemas, no impedimento da morte de inúmeras pessoas e na redução de angústias e sofrimentos, mas eles não podem ser os únicos suportes para se compreender ou identificar os distintos processos vivenciados pelos usuários. Se eles forem bem dimensionados àquelas situações em que realmente podem ser úteis para complementar a clínica no caso dos exames e para solucionar situações pontuais no caso dos medicamentos, contribuem, com as suas finalidades e utilidades, para um nível maior de saúde da população.

Da dimensão avaliativa, este quadrante traz as palavras fila e demora. No que tange à fila, ressalta-se que esta é uma situação das mais presentes no contexto do sistema de saúde, sendo noticiadas cotidianamente nas portas dos hospitais, das unidades básicas e dos ambulatórios. As filas significam uma porta menor do que a demanda pelas ações e serviços de saúde, impedindo o seu alcance a todos aqueles que procuram as instituições no interior do SUS. Implicam em uma organização em que o princípio da universalidade vê-se continuamente ameaçado pela possibilidade do acesso ser negado e o sistema, 
assim, apresentar-se desconfigurado e desenraizado de seus princípios. Além disso, em diversas situações elas se mostram profundamente perversas e frustrantes para as pessoas que não conseguem ter as suas necessidades satisfeitas, após horas de espera, de cansaço e de estresse físico e mental.

Outra questão relacionada às filas é o congestionamento do sistema nos níveis de maior complexidade, especialmente nas instituições terciárias e quaternárias, esgotando os recursos e as vagas existentes com situações que poderiam ser resolvidas em unidades básicas ou, no máximo, nos ambulatórios. Dessa maneira, podem ser encontrados episódios de crise hipertensiva e distúrbios neurovegetativos que poderiam ser atendidos (o primeiro) ou prevenidos (o segundo) na porta de entrada do sistema. Este fato pode estar relacionado, ainda, à estrutura burocrática das unidades de saúde, que dificultam o acesso fazendo com que a procura por ações e serviços se dêem em situações de emergência.

Destaca-se, ainda, a universalização do sistema após a implantação do SUS sem uma política estratégica e financeira que permitisse tal desafio. Para piorar o quadro que seria enfrentado, o Governo Collor provocou um aperto nos investimentos em saúde, gerando um caos antes não experimentado: a abertura das portas e aumento dos gastos em concomitância com cortes de verbas e desaceleração do investimento estatal nas dimensões sociais e básicas ${ }^{(22)}$. Os reflexos desse fato podem ser vistos até hoje e uma de suas conseqüências mais visíveis é o fenômeno da fila no atendimento à saúde.

Junto com fila, a demora é colocada como uma avaliação negativa do sistema e é associada semanticamente a atendimento, medicamentos e exames. Neste processo, normalmente, perde-se a continuidade do tratamento e oportunidades que poderiam gerar maior qualidade no cotidiano dos sujeitos e, em alguns casos, até mesmo a manutenção da vida, postergando soluções que, em princípio, estariam próximas e seriam de fácil acesso.

Em algumas situações, a demora pode ser consequêencia da falta de estrutura do sistema de saúde que não possui recursos materiais e/ou humanos para dar continuidade ao processo de assistência. Em outras, por falta de vaga de retorno para o profissional e/ou instituição que controla o atendimento de um determinado indivíduo, apesar das etapas intermediárias terem sido feitas com sucesso. Por fim, ressalta-se, novamente, o importante papel do princípio da hierarquização que, ao não ser concretizado, facilita ou propicia o surgimento de casos de gargalo no fluxo do sistema e, conseqüentemente, de demora no processo de atendimento e de chegada ao seu término.

A segunda periferia apresenta novamente todas as dimensões que estão contidas na estrutura da representação do sistema para os usuários. A de finalidade se faz presente através dos léxicos atender-todos, internação e limpeza; a espacial em função da citação de uma unidade hospitalar específica que é a emergência; a avaliativa, pelo destaque dado à desigualdade; e a conceitual pela definição do sistema como aquele dirigido aos pobres, através da expressão baixa-renda.

Como o sistema periférico mostra a relação dessa representação com a realidade, percebe-se um desdobramento do núcleo central neste sistema. Assim, hospital se desdobra em emergência que, para nossa surpresa, foi a única unidade hospitalar citada, o que parece representar o seu grau de importância para os sujeitos estudados. A dimensão da finalidade evoca o princípio da universalidade (atender-todos), reforça o hospital como o lócus privilegiado de atendimento (internação) e traz a higiene como um dos objetivos do SUS (limpeza), sendo a mais freqüente neste quadrante.

A dimensão avaliativa, por sua vez, foi a única transversal à análise como conseqüência do seu aparecimento em todos os quadrantes. A desigualdade apontada nesta dimensão possui sua raiz na agressão ao princípio da eqüidade, em que todos devem ter as suas necessidades atendidas de acordo com a sua situação e suas demandas, provavelmente pela vivência de situações em que algumas pessoas foram privilegiadas no processo de atendimento, sem que este privilégio tivesse relação com a gravidade do caso ou com as suas necessidades.

Quando comparamos as representações dos usuários com os profissionais ${ }^{(6,14)}$, podemos perceber que se trata de duas representações distintas, tendo a dos usuários um traço eminentemente positivo e a dos profissionais, negativo. A positividade trazida pelos usuários chama a atenção em função da complexa realidade que permeia o sistema e que, em uma análise mais superficial, poderia ter deixado uma marca mais profunda na reconstrução cognitiva do sistema. Por outro lado, os profissionais, além de estarem inseridos no quadro funcional do sistema, também possuem uma relação com ele como usuários, o que pode ter potencializado essa representação negativa.

O ponto comum entre os dois grupos é a palavra atendimento e, conseqüentemente, a dimensão finalidade no núcleo central de ambas as representações. Esta observação demonstra o quanto o conjunto de profissionais e usuários se preocupam com a concretização do SUS, o primeiro por fazê-lo acontecer e o segundo por necessitar dele, às vezes de forma vital, em seus cotidianos. Outro ponto a ser aprofundado é a oposição estabelecida entre igualdade e desigualdade, sendo o primeiro trazido pelos profissionais em sua zona de contraste e o segundo pelos usuários, na segunda periferia. Igualdade e desigualdade são pontos de vistas distintos para o mesmo fenômeno: o acesso a ações e serviços de saúde, do lado de quem evoca um princípio para organizar o sistema de saúde e do lado de quem sofre os efeitos da sua implantação ou da sua não implantação.

\section{CONSIDERAÇÕES FINAIS}

Os usuários do sistema de saúde possuem uma forma particular de compreendê-lo, definindo-o, vendo suas finalidades, o espaço onde ele se concretiza em suas experiências e avaliando-o a partir dessas mesmas experiências, daquilo que ouve a seu respeito e das informações que recebe a todos os momentos, inclusive da grande mídia. A partir deste conjunto apresentam atitudes diante do mesmo, internalizando alguns dos seus princípios e constroem determinado grau de afetividade, reconstruindo-o nesse processo de interação constante a cada nova experiência, nova notícia ou nova opção. Dessa maneira, o sistema não é apenas algo externo aos sujeitos, 
objetivo em sua dimensão concreta e estrutural, mas também interno no processo de sua reconstrução cognitiva a partir de determinadas características grupais.

O sistema, para os usuários, é reconstruído a partir de sua faceta prática e mesmo o seu suporte teórico, como os princípios, é incorporado a partir deste aspecto. Neste sentido, a universalidade se mostra através do atendimento e a equidade a partir de seu oposto, a desigualdade. O conhecimento, as opiniões alheias e as informações recebidas gravitam ao redor da experiência prática, dando-lhe sentido e esta, por sua vez, faz uma triagem do saber recebido, permanecendo somente aquele que possui coerência e afinidade com a vivência e a experiência.
Destaca-se a necessidade de uma política pública que avance na implantação do SUS e que, além disso, produza transformações nas representações sociais dos sujeitos, o que, por sua vez, gerará mudanças em suas atitudes e na relação que estabelece com o próprio sistema. No aspecto micro-político, os profissionais de saúde podem exercer um importante papel no processo de atendimento à clientela, estimulando a sua participação ativa no sistema, o conhecimento dos seus direitos e o exercício do controle social nas instâncias possíveis, a fim de torná-lo melhor e mais próximo das necessidades da população, em sua maioria marcada e sofrida com um grau de miséria que fere a dignidade humana.

\section{REFERÊNCIAS}

1. Levcovitz E, Lima LD, Machado CV. Política de saúde nos anos 90. Ciênc Saúde Coletiva 2001; 6(2):269-81.

2. Moscovici S. La psychanalyse, son image et son public. Paris: P.U.F.; 1976.

3. Abric JC. Pratiques sociales et représentations. Paris: Presses Universitaires de France; 1994.

4. Jodelet D. Représentations sociales: un domaine en expansion. In: Jodelet D, organizadora. Les représentations sociales. Paris: Presses Universitaires de France; 1989. p. 17-44.

5. Vergès $P$. Appoche du noyau central: proprietès quantitatives et structurales. In: Guimelli C, organizador. Textes de Base in Sciences Sociales: Structures et Transformation des Représentations Sociales. Paris: Delachaux et Niestlé; 1994. p. 233-53.

6. Oliveira DC, Sá CP, Gomes AMT, Ramos RS, Pereira NA, Santos WCR. A política pública de saúde brasileira: representação e memória social de profissionais. Cad. Saúde Pública 2008; 24(1): 197-206.

7. Ministério da Saúde (BR). Um panorama geral do SUS: balanços e perspectivas. Brasília: Ministério da Saúde; 2009.

8. Campos GWS. Análise crítica das contribuições da saúde coletiva à organização das práticas de saúde no SUS. In: Fleury S, organizadora. Saúde e democracia: a luta do CEBES. São Paulo: Lemos editorial; 1997. p.113-24.

9. Pontes APM, Oliveira DC, Gomes AMT, Cesso RGD. O que a mídia não mostra: as facilidades de acesso no SUS reveladas por seus usuários. In: Anais do 60 Congresso Brasiliero de Enfermagem; 2008; Belo Horizonte (MG), Brasil. Belo Horizonte: ABEn; 2008. p. 1-14.

10. Espírito Santo, CC, Vellasques AP, Gomes AMT, Oliveira DC, Pontes APM; Campos LA. O atendimento profissional no contexto do SUS: um estudo de Representações Sociais. In: Anais da II semana de Saúde Coletiva da UFRJ; 2008; Rio de Janeiro: Editora UFRJ; 2008. p. 1-2

11. Backes VMS, Martins ST, Ferraz F, Schmidt SMS, Prado ML, Lino MMotta et al. Competência dos enfermeiros em problematizar a realidade do serviço de saúde no contexto do Sistema Único de Saúde. Texto Contexto Enferm. 2007; 16(4): 727-736.

12. Borenstein MS. Poder da enfermagem no espaço hospitalar. Texto Contexto Enferm. 2000;9(3): 42-53

13. Oliveira EXG, Travassos C, Carvalho MS. Acesso à internação hospitalar nos municípios brasileiros em 2000: territórios do Sistema Único de Saúde. Cad. Saúde Pública 2004; 20(Suppl 2): 298-309.

14. Oliveira DC, Gomes AMT, Acioli S, Sá CP. O Sistema Único de Saúde na cartografia mental de profissionais de saúde. Texto Contexto Enferm. 2007;16(3): 377-386.

15. Kovács MJ. Bioética nas questões da vida e da morte. Psicol. USP 2003; 14(2): 115-167.

16. Cabral IE. Aliança de saberes no cuidado e estimulação da criança-bebê: concepções de estudantes e mães no espaço acadêmico de enfermagem. Rio de Janeiro: Escola Anna Nery; 1999.

17. Capra F. O ponto de mutação. São Paulo: Cultrix; 1982.

18. Boff L. Saber Cuidar - ética do humano, compaixão pela terra. Petrópolis: Vozes; 1999.

19. Brasil. Lei Orgânica de Saúde $n^{\circ}$. 8.080, de 19 de setembro de 1990. Dispõe sobre as condições para a promoção, proteção e recuperação de saúde, a organização e o funcionamento dos serviços correspondentes e da outras providencias. Diário Oficial da União 1990; 20 set.

20. Gomes AMT, Oliveira DC. A representação social da autonomia profissional do enfermeiro na Saúde Pública. Rev Bras Enferm. 2005;58(4): 393-398.

21. Gomes AMT, Oliveira DC. Espaço autônomo e papel próprio: representações de enfermeiros no contexto do binômio saúde coletiva-hospital. Rev Bras Enferm. 2008; 61(2):178-185.

22. Parker R. Introdução. In: Parker R, organizador. Políticas, instituições e Aids, enfrentando a epidemia no Brasil. Rio de Janeiro: Jorge Zahar 1997. p. 7-15. 